\title{
On The Effect of Random Variations in the Parameter of Arrival and Service Time Distributions on Various Queue Characteristics in (M/M/1): ( $\infty / F I F O)$ Queue System Model
}

\author{
Jaideep Goel, Ph.D \\ Forest Department (U.P.), 17, Rana \\ Pratap Marg, Lucknow-226001
}

\author{
Birjesh Sharma, Ph.D \\ J.P Institute of Engg. \&Technology \\ Meerut- 250001(U.P.) INDIA
}

\author{
P. K. Gupta, Ph.D \\ D.A.V.(P.G.)College, \\ MuzaffarNagar-251001(U.P.) INDIA
}

\begin{abstract}
The present study deal with the development of statistical methodology for updating the basic arrival and service time distributions in respect of prior variations. These updated arrival and services time distributions provide us the modified form of traffic intensity as the ratio of updated mean service time to updated mean inter-arrival time. As such all the basic queue characteristics will be developed in the changed scenario.
\end{abstract}

\section{Keywords}

Traffic Intensity, Arrival and Service Rates, Prior Distribution, Compound Distribution.

\section{INTRODUCTION}

The characteristics of various queue systems have been analyzed by using their respective probability mass functions (p.m.f.). With exponential arrival and service time distributions, the traffic intensity is defined as the ratio of the arrival rate to the service rate and various queue's system have been defined using this parameter in studies like (Ackoff and Sasiei, 1968; Taha, 1976). In reliability theory, this ratio is also known as availability ratio. Sharma and Bhutani (1992, 1994) studied the posterior analysis of the system availability and developed the Bay's point and interval estimators for availability by assuming the prior distribution for the parameter involved in failure and repair time distributions. Following the concept, a study regarding statistical inferences on various important performance measures has been done by Sharma and Kumar (1999) for a (M/M/1) ( $\infty$ / FIFO) queue system model. In this continuation, Maurya (2004, 2005), Gupta et. al. (2009) have confined their considerable attention to analyze different types of queue system models regarding statistical inferences on its useful characteristics. However, while recording arrival and service information for a large interval of time, it is reasonable to assume random variations in the parameter involve in the arrival and service time distributions. Here it should be recognized that prior do have an impact on the basic distribution and therefore updating these basic distributions in its parameter is another important aspect for analyzing the queue characteristics of the model in changed scenario. The variations in the parameter can be neutralized by averaging as we do in the case of compound distribution of the concern variable (Johnson and Kotz, 1969).

In the light of the above discussion, the present study deals with the development of the methodology for updating the basic distributions in respect of prior variations in arrival and service time distributions. These updated distributions have been used to study the robust character of various queue characteristics in (M / M / 1): ( $\infty$ / FIFO) queue system model.

\section{PRELIMINARY IDEAS ASSUMPTIONS USED}

(a) The probability mass function (p.m.f) of the system size distribution of the typical queue in $(\mathrm{M} / \mathrm{M} / 1):(\infty / \mathrm{FIFO})$ queue system model is given by

$P(X=x)=(1-\rho) \rho^{x} \quad ; \quad 0<\rho<\infty, X=0,1,2 \ldots ;$

where the notations used in (1) have their significance as following -

$$
\begin{aligned}
& \mathrm{P}(\mathrm{X}=\mathrm{x}) \quad \text { : } \begin{array}{l}
\text { Stationary probability that there are } \mathrm{x} \\
\text { customers in the system }
\end{array} \\
& \rho \quad: \quad \text { The traffic intensity i.e. } \rho=\frac{\lambda}{\mu} \text { i.e. } \\
& \\
& \text { the ratio of the mean service time to } \\
& \text { mean inter-arrival time }
\end{aligned}
$$

(b) Based on p.m.f. in (1), some important characteristics of the system are

(i) Average queue length, say $\mathrm{L}_{\mathrm{s}}$, is

$$
\mathrm{L}_{\mathrm{s}}=\mathrm{E}(\mathrm{X})=\frac{\rho}{(1-\rho)}=\frac{\lambda}{(\mu-\lambda)}
$$

(ii) Average length of waiting line $\mathrm{L}_{\mathrm{q}}$, will be

$$
\mathrm{L}_{\mathrm{q}}=\mathrm{E}(\mathrm{X}-1)=\frac{\rho^{2}}{(1-\rho)}=\frac{\lambda^{2}}{\mu(\mu-\lambda)^{2}}
$$

(iii) The expected length of non empty queue $(\mathrm{L} / \mathrm{L}>0)$ will be

$$
(\mathrm{L} / \mathrm{L}>0)=\frac{1}{(1-\rho)}=\frac{\mu}{(\mu-\lambda)}
$$

(iv) The probability of minimum queue size being $n_{0}$, i.e.

$$
\mathrm{Q}_{\mathrm{m}}=\mathrm{P}\left(\mathrm{x} \geq \mathrm{n}_{0}\right)=\rho^{\mathrm{n}_{0}}=\left(\frac{\lambda}{\mu}\right)^{\mathrm{n}_{0}}
$$

(v) The variance of the queue length will be

$$
\mathrm{V}_{\mathrm{s}}=\mathrm{E}(\mathrm{X}-\mathrm{E}(\mathrm{X}))^{2}=\frac{\rho}{(1-\rho)^{2}}=\frac{\lambda \mu}{(\mu-\lambda)^{2}}
$$


(vi) The Co-efficient of variation for $\mathrm{x}$, say $\mathrm{CV}$, will be

$$
\mathrm{CV}_{\mathrm{s}}=\frac{\sqrt{\mathrm{V}_{\mathrm{s}}}}{\mathrm{L}_{\mathrm{s}}} * 100
$$

\section{STATISTICAL BACKGROUND}

For developing the procedure, it is assumed that

(a) The arrival time distribution for the system is exponential with p.d.f.

$\mathrm{f}\left(\mathrm{t}_{1}, \lambda\right)=\lambda \mathrm{e}^{-\lambda \mathrm{t}_{1}} ;\left(\mathrm{t}_{1}, \lambda\right)>0$

Here $\lambda$ is the arrival rate and

$\mathrm{E}\left(\mathrm{T}_{1}\right)=$ Mean Inter-arrival time $=\frac{1}{\lambda}$,

$\mathrm{V}\left(\mathrm{T}_{1}\right)=\frac{1}{\lambda^{2}}$

(b) The service time distribution for the system is also exponential with p.d.f.

$$
f\left(t_{2}, \mu\right)=\mu e^{-\mu t_{2}} \quad ;\left(t_{2}, \mu\right)>0
$$

Here $\mu$ is the survival rate and

$\mathrm{E}\left(\mathrm{T}_{2}\right)=$ Mean service time $=\frac{1}{\mu}$,

$$
\mathrm{V}\left(\mathrm{T}_{2}\right)=\frac{1}{\mu^{2}} \text {. }
$$

(c) The designer's prior belief about the arrival rate $\lambda$ of the system is represented by a gamma distribution having p.d.f.

$\mathrm{g}(\lambda, \mathrm{m}, \mathrm{n})=\frac{\mathrm{m}^{\mathrm{n}}}{\Gamma \mathrm{n}} \lambda^{\mathrm{n}-1} \mathrm{e}^{-\mathrm{m} \lambda} ;(\lambda, \mathrm{m}, \mathrm{n})>0 . .(4)$

Here, $\mathrm{E}(\lambda)=\mathrm{n} / \mathrm{m}, \mathrm{V}(\lambda)=\frac{\mathrm{n}}{\mathrm{m}^{2}}$ Similarly,

the prior distribution for the service rate $\mu$ is taken as

$\mathrm{g}(\mu, \mathrm{u}, \mathrm{v})=\frac{\mathrm{u}^{\mathrm{v}}}{\Gamma \mathrm{v}} \mu^{\mathrm{v}-1} \mathrm{e}^{-\mathrm{u} \mu} ;(\mu, \mathrm{u}, \mathrm{v})>0$

Here, $E(\mu)=v / u, V(\mu)=\frac{v}{u^{2}}$

(d) In view of (2) and (4) the compound distribution of $\mathrm{T}_{1}$ is

$$
\begin{gathered}
\mathrm{f}_{1}\left(\mathrm{t}_{1}, \mathrm{a}, \mathrm{b}\right)=\int_{\mathrm{o}}^{\infty} \mathrm{f}\left(\mathrm{t}_{1}, \lambda\right) \mathrm{g}(\lambda, \mathrm{m}, \mathrm{n}) \mathrm{d} \lambda \\
=\frac{\mathrm{n}(\mathrm{m})^{\mathrm{n}}}{\left(\mathrm{t}_{1}+\mathrm{m}\right)^{\mathrm{b}+1}}
\end{gathered}
$$

Here, $\mathrm{E}\left(\mathrm{T}_{1}\right)=$ updated the mean inter-arrival time =

$$
\frac{m}{n-1}, V\left(T_{1}\right)=\frac{m^{2} n}{(n-1)^{2}(n-1)}
$$

In the compounding process, the variations in $\lambda$ get neutralized on taking expectation over the function $f_{1}\left(t_{1}, \lambda\right)$ in respect of $\lambda$ for fixed $T_{1}$. Consequently, the compound distribution in (6) is interpreted as an updated basic arrival time distribution when the variation in $\lambda$ have been condensed or neutralized.

(e) Similarly, In view of (3) and (5) the compound distribution of $\mathrm{T}_{2}$ is

$$
\begin{aligned}
f_{1}\left(t_{2}, u, v\right) & =\int_{0}^{\infty} f\left(t_{2}, \mu\right) g(\mu, u, v) d \mu \\
& =\frac{v u^{v}}{\left(t_{2}+u\right)^{v+1}}
\end{aligned}
$$

Here, $\mathrm{E}\left(\mathrm{T}_{2}\right)=$ updated mean service time $=\frac{\mathrm{u}}{\mathrm{v}-1}$ and $\mathrm{V}\left(\mathrm{T}_{2}\right)=\frac{\mathrm{u}^{2} \mathrm{v}}{(\mathrm{v}-1)^{2}(\mathrm{v}-1)}$

As per earlier argument, the compound distribution in (7) is also interpreted as an updated basic service time distribution. Thus, in the process one gets a basic and an updated basic service time distributions in (3) and (7) respectively. Similarly, a basic and updated basic arrival time distributions are given in (2) and (6) respectively. These distributions enable us to analyse the queue characteristics of the model in the following two specific situations.

(i) When the basic arrival and service time distributions as given in (2) and (3) respectively used in the analysis, where the parameters involved are treated as constant

(ii) When the updated basic arrival and service time distributions as given in (6) and (7) respectively used in the analysis which accounts for variations in the parameters of basic distributions in (4) and (5).

\section{QUEUE CHARACTERISTICS OF THE MODEL WHEN THE PARAMETERS INVOLVED IN ARRIVAL AND SERVICE TIME DISTRIBUTIONS ARE TAKEN TO BE RANDOM VARIABLE}

In this case, the respective updated arrival $\left(\mathrm{T}_{1}\right)$ and service time ( $\mathrm{T}_{2}$ ) distributions, as given in (6) and (7) respectively, are used for getting expressions for various queue characteristics of the model with identical conditions in changed setup. On using these distributions, initially, the traffic intensity $(\rho)$ can be modified as the ratio of the updated mean service time to updated mean inter-arrival time. Mathematically

$$
\rho^{*}=\frac{E\left(T_{2}\right)}{E\left(T_{1}\right)}=\frac{u(n-1)}{m(v-1)}
$$


Now, when $\rho$ is modified as above, various queue characteristics of the present model are updated as under :

(i) Average queue length, say $\mathrm{L}_{\mathrm{s}}^{*}$, is

$$
\begin{aligned}
\mathrm{L}_{\mathrm{s}}^{*} & =\frac{\rho^{*}}{\left(1-\rho^{*}\right)} \\
& =\frac{\mathrm{u}(\mathrm{n}-1)}{\mathrm{m}(\mathrm{v}-1)-\mathrm{u}(\mathrm{n}-1)}
\end{aligned}
$$

(ii) Average length of waiting line $\mathrm{L}_{\mathrm{q}}^{*}$, will be

$$
\begin{aligned}
\mathrm{L}_{\mathrm{q}}^{*} & =\frac{\rho^{* 2}}{\left(1-\rho^{*}\right)} \\
& =\frac{\mathrm{u}^{2}(\mathrm{n}-1)^{2}}{\mathrm{~m}(\mathrm{v}-1)[\mathrm{m}(\mathrm{v}-1)-\mathrm{u}(\mathrm{n}-1)]}
\end{aligned}
$$

(iii) The probability of minimum queue size being $\mathrm{n}_{0}$, i.e.

$$
\begin{aligned}
\mathrm{Q}_{\mathrm{m}}^{*} & =\left(\rho^{*}\right)^{\mathrm{n}_{0}} \\
& =\left(\frac{\mathrm{u}(\mathrm{n}-1)}{\mathrm{m}(\mathrm{v}-1)}\right)^{\mathrm{n}_{0}}
\end{aligned}
$$

(iv) The expected length of non empty queue,

$$
\begin{aligned}
& \left(\mathrm{L}^{*} / \mathrm{L}^{*}>0\right) \text {, will be } \\
& \qquad \begin{aligned}
\left(\mathrm{L}^{*} / \mathrm{L}^{*}>0\right) & =\frac{1}{\left(1-\rho^{*}\right)} \\
& =\frac{\mathrm{m}(\mathrm{v}-1)}{[\mathrm{m}(\mathrm{v}-1)-\mathrm{u}(\mathrm{n}-1)]}
\end{aligned}
\end{aligned}
$$

(v) The variance of the queue length will be

$$
\begin{aligned}
\mathrm{V}_{\mathrm{S}}^{*} & =\frac{\rho^{*}}{\left(1-\rho^{*}\right)^{2}} \\
& =\frac{\mathrm{mu}(\mathrm{n}-1)(\mathrm{v}-1)}{[\mathrm{m}(\mathrm{v}-1)-\mathrm{u}(\mathrm{n}-1)]^{2}}
\end{aligned}
$$

(vi) The Co-efficient of variation for $\mathrm{X}$, say $\mathrm{CV}_{\mathrm{S}}^{*}$, will be

$$
\mathrm{CV}_{\mathrm{s}}^{*}=\frac{\sqrt{\mathrm{V}_{\mathrm{s}}^{*}}}{\mathrm{~L}_{\mathrm{s}}^{*}} * 100
$$

\section{DISCUSSION}

For analyzing the effect of random variations in arrival and service time distributions, we compare the queue characteristics as given in subsection 2 (b) with those given in section 4.0. Choosing suitability of the parameters, the corresponding value of the $\lambda=E(\lambda)=\frac{\mathrm{n}}{\mathrm{m}}$ and $\quad \mu=$

$E(\mu)=\frac{v}{u}$ may be used for analyzing the effect of random variations on various queue characteristics. The estimates of the various queue characteristics with variations in $\lambda$ [or $\mathrm{E}(\lambda)$ ], (while $\mu$ is fixed) are shown in [Table-1] and [Table-2] respectively. Similarly, for fixed $\lambda$, and with variations in $\mu$ [or $\mathrm{E}(\mu)]$, the estimates of the various queue characteristics are shown in Table-3 [Table-4] respectively .

\section{ANALYSIS}

From Table-1 and 2, we observe that when $\lambda=0.50$, the corresponding value of $\mathrm{L}_{\mathrm{s}}$ is 1.667. However, for $[\mathrm{m}=10, \mathrm{n}=$ 5 or $\lambda=\mathrm{E}(\lambda)=0.50],[\mathrm{m}=10, \mathrm{n}=6$ or $\lambda=\mathrm{E}(\lambda)=0.60]$, and $[\mathrm{m}=10, \mathrm{n}=7$ or $\lambda=\mathrm{E}(\lambda)=0.70]$ the corresponding values of $L_{s}$, say $L_{s}^{*}$ are $1.333,2.5000$ and 6.000 respectively. The trends in Table-1and 2 values clearly reveals that these updated values are tend to be smaller up to a certain point, but thereafter, these values tend to be uniformly higher when $E(\lambda)$ $\geq \lambda$. On the other hand, for $\mathrm{E}(\lambda)<\lambda$, the

By the same way from Table- 3 and 4, we observe that when $\mu$ $=0.60$, the corresponding value of Ls is 0.5000 . However, for $[\mathrm{u}=10, \mathrm{v}=6$ or $\mu=\mathrm{E}(\mu)=0.60],[\mathrm{u}=10, \mathrm{v}=7$ or $\quad \mu$ $=\mathrm{E}(\mu)=0.70]$, and $[\mathrm{u}=10, \mathrm{v}=8$ or $\mu=\mathrm{E}(\mu)=0.80]$ the corresponding values of Ls, say $\mathrm{L}_{\mathrm{s}}^{*}$ are $0.2500,0.1667$ and 0.1429 respectively. These trends clearly reveals that all these updated values are tend to be smaller up to a certain point, but thereafter, these values tend to be uniformly higher when $\mathrm{E}(\mu) \leq \mu$

. On the other hand, for $E(\lambda)>\lambda$, the updated values of queue characteristics are tend to be uniformly smaller.

On comparing the variations in $\mathrm{CV}_{\mathrm{s}}^{*}$ in respect of $\lambda$ and $E(\lambda)$ in Table-1 and 2 respectively, we observe that the estimates tend to be more and more consistent as either $\lambda$ or $\mathrm{E}(\lambda)$ increases. Similarly, on comparing the variations in $\mathrm{CV}_{\mathrm{s}}^{*}$ respectively, we observe that the estimates tend to be less and less consistent as either $\mu$ or $E(\mu)$ increases. Finally, the conclusion is that, the queue characteristics of a $(\mathrm{M} / \mathrm{M} / 1)$ : $(\infty / F I F O)$ queue system model are observed to be non-robust and as such, this model should be very cautiously used whenever we suspect variations in arrival and service rates or in $\rho$. 
Table-1

Estimates of queue characteristics when basic arrival and service time distributions are used $(\mu=E(\mu)=0.8)$

\begin{tabular}{|l|l|l|l|l|l|l|}
\hline$\lambda$ & $\mathrm{L}_{\mathrm{s}}$ & $\mathrm{L}_{\mathrm{q}}$ & $\mathrm{Q}_{\mathrm{m}}$ & $\mathrm{V}_{\mathrm{s}}$ & $(\mathrm{L} / \mathrm{L}>0)$ & $\mathrm{C} \mathrm{V}_{\mathrm{s}}$ \\
\hline 0.2 & 0.3333 & 0.0833 & 0.0156 & 0.4444 & 1.3333 & 200.01 \\
\hline 0.3 & 0.6000 & 0.2250 & 0.0527 & 0.9600 & 1.6000 & 163.29 \\
\hline 0.4 & 1.0000 & 0.5000 & 0.1250 & 2.0000 & 2.0000 & 141.42 \\
\hline 0.5 & 1.6667 & 1.0417 & 0.2441 & 4.4444 & 2.6667 & 126.49 \\
\hline 0.6 & 3.0000 & 2.2500 & 0.4219 & 12.0000 & 4.0000 & 115.47 \\
\hline 0.7 & 7.0000 & 6.1250 & 0.6699 & 56.0000 & 8.0000 & 106.90 \\
\hline
\end{tabular}

Table-2

Estimates of queue characteristics when updated basic arrival and service time distributions are used $(\mathbf{m}=10, \mu=\mathbf{E}(\mu)=0.8$,

\begin{tabular}{|l|l|l|l|l|l|l|l|}
\hline $\mathrm{n}$ & $\lambda=\mathrm{E}(\lambda)$ & $\mathrm{L}_{\mathrm{s}}^{*}$ & $\mathrm{~L}_{\mathrm{q}}$ & $\mathrm{Q}_{\mathrm{m}}^{*}$ & $\mathrm{~V}_{\mathrm{s}}^{*}$ & $\left(\mathrm{~L}^{*} / \mathrm{L}^{*}>0\right)$ & $\mathrm{CV}_{\mathrm{s}}^{*}$ \\
\hline 2 & 0.2 & 0.1667 & 0.0238 & 0.0029 & 0.1944 & 1.1667 & 264.49 \\
\hline 3 & 0.3 & 0.4000 & 0.1143 & 0.0233 & 0.5600 & 1.4000 & 187.08 \\
\hline 4 & 0.4 & 0.7500 & 0.3214 & 0.0787 & 1.3125 & 1.7500 & 152.75 \\
\hline 5 & 0.5 & 1.3333 & 0.7619 & 0.1865 & 3.1111 & 2.3333 & 132.29 \\
\hline 6 & 0.6 & 2.5000 & 1.7857 & 0.3644 & 8.7500 & 3.5000 & 118.32 \\
\hline 7 & 0.7 & 6.0000 & 5.1428 & 0.6297 & 42.0000 & 7.0000 & 108.01 \\
\hline
\end{tabular}

Table-3

Estimates of queue characteristics when basic arrival and service time distributions are used $(\lambda=E(\lambda)=0.2)$

\begin{tabular}{|l|l|l|l|l|l|l|}
\hline$\mu$ & $\mathrm{L}_{\mathrm{s}}$ & $\mathrm{L}_{\mathrm{q}}$ & $\mathrm{Q}_{\mathrm{m}}$ & $\mathrm{V}_{\mathrm{s}}$ & $(\mathrm{L} / \mathrm{L}>0)$ & $\mathrm{C} \mathrm{V}_{\mathrm{s}}$ \\
\hline 0.3 & 2.0000 & 1.3333 & 0.2963 & 6.0000 & 3.0000 & 122.47 \\
\hline 0.4 & 1.0000 & 0.5000 & 0.1250 & 2.0000 & 2.0000 & 141.42 \\
\hline 0.5 & 0.6667 & 0.2667 & 0.0640 & 1.1111 & 1.6667 & 158.11 \\
\hline 0.6 & 0.5000 & 0.1667 & 0.370 & 0.7500 & 1.5000 & 173.21 \\
\hline 0.7 & 0.4000 & 0.1143 & 0.0233 & 0.5600 & 1.4000 & 187.08 \\
\hline 0.8 & 0.3333 & 0.0833 & 0.0156 & 0.4444 & 1.3333 & 200.01 \\
\hline 0.9 & 0.2857 & 0.0127 & 0.0109 & 0.3673 & 1.2857 & 212.13 \\
\hline
\end{tabular}

Table-4

Estimates of queue characteristics when updated basic arrival and service time distributions are used $(u=10, \lambda=E(\lambda)=0.2$, $\mathrm{m}=10, \mathrm{n}=2$ )

\begin{tabular}{|l|l|l|l|l|l|l|l|}
\hline $\mathrm{v}$ & $\mu=\mathrm{E}(\mu)$ & $\mathrm{L}_{\mathrm{s}}^{*}$ & $\mathrm{~L}_{\mathrm{q}}$ & $\mathrm{Q}_{\mathrm{m}}^{*}$ & $\mathrm{~V}_{\mathrm{s}}^{*}$ & $\left(\mathrm{~L}^{*} / \mathrm{L}^{*}>0\right)$ & $\mathrm{CV}_{\mathrm{s}}^{*}$ \\
\hline 3 & 0.3 & 1.0000 & 0.5000 & 0.1250 & 2.0000 & 2.0000 & 141.42 \\
\hline 4 & 0.4 & 0.5000 & 0.1667 & 0.0370 & 0.7500 & 1.5000 & 173.21 \\
\hline 5 & 0.5 & 0.3333 & 0.0833 & 0.0156 & 0.4444 & 1.3333 & 200.01 \\
\hline 6 & 0.6 & 0.2500 & 0.0500 & 0.0080 & 0.3125 & 1.2500 & 223.61 \\
\hline 7 & 0.7 & 0.2000 & 0.0333 & 0.0046 & 0.2400 & 1.2000 & 244.95 \\
\hline 8 & 0.8 & 0.1667 & 0.0238 & 0.0029 & 0.1944 & 1.1667 & 264.49 \\
\hline 9 & 0.9 & 0.1429 & 0.0178 & 0.0019 & 0.1633 & 1.1428 & 282.79 \\
\hline
\end{tabular}




\section{REFERENCE}

[1] Ackoff ,R .L. and Sasieni, M.W.(1968), "Fundamental of Operation Research" Wiley Eastern Ltd. New York, USA.

[2] Gupta, P.K. Jaideep Goyal and Rajesh Kumar (2008), "On the Robustness of the Queue Characteristics in Power Supply System Modes" Int. J. Essential Sciences, Vol.-2, No.-2, 42-48.

[3] Gupta, P.K. Jaideep Goyal and Rajesh Kumar (2009), "Posterior Analysis of the Queue Characteristics in Power Supply System Modes" Bulletin of the Allahabad Mathematical Society, Vol. 4, Part-2, 297-306.

[4] Johnson, N. L. and Kotz, S.(1969), "Discrete Distribution" John Wiley and Sons New York, USA.

[5] Kapur, J. N. and Saxena, S.C. (1984), "Mathematical Statistics", 12th Edision, S. Chand \& Co.Ltd. New Delhi.
[6] Maurya, V. N. (2005), "Inference on Operating Characteristics of the Queue in Power Supply System Model", Proceeding of National Seminar on Mathematics and Computer Sciences Sponsored by UGC and organized by S.D. (P.G.)College, Muzaffarnagar,419422 .

[7] Sharma, K.K. and Bhutani, R. K. (1992), "Bayesian Analysis of System Availability" Micro electrn Reliab. 33(6) 809-811.

[8] Sharma, K.K. and Bhutani, R. K. (1994), "Analysis of Posterior Availability Distribution of Series and Paalel System" Micro electron Reliab. 34(2) 379-381.

[9] Sharma, K.K. and Kumar, V.(1999), "Inferences on (M/M/1): ( $\infty / F I F O)$ Queue System" Opsearch, Vol. 36, No. 1, pp. 26-34.

[10] Taha, H.A. (1976), “Operation Research, An Introduction" Macmillan, New York, U.S.A. 